\title{
Educational ecosystem development based on quality management standards
}

\author{
Elena Levina*, Elena Prokofieva \\ Institute of Pedagogy, Psychology and Social Problems, 420039, Isaeva st., 12, Kazan, Russia
}

\begin{abstract}
The educational system is sensitive to all changes in the world space. The transition to a digital society is determined by significant changes in the philosophical foundations of human activity and creating products, especially intellectual ones. The information and digital revolutions have significantly changed the spheres of cognition, perception and human activity, putting them on the rails of continuous education in an actively developing dynamic world. In order to evolve, it is necessary to transfer the existing system of knowledge and sciences to the new, digital generation of people, to form mechanisms of continuous learning, to generate innovations - the solution to this problem lies with the education system, referring to all its levels. The change in the education model is not only about the digitalization of educational processes. The "humancentered" approach is global. The authors consider the methodology for the development of educational ecosystems as a new norm of educational activity, revealing the concepts of educational ecology and analyzing the principles of implementing the ecosystem approach from the standpoint of achieving the quality of education.
\end{abstract}

\section{Introduction}

The exponential growth of information, the formation of a new system of knowledge and the actualization of certain value orientations for a new civilization form a different subject matter for scientific socio-humanitarian research in the center of which is the processes of human development.

Obviously, pedagogical science plays a special role here, requiring serious methodological updates and practice-oriented transformations, including the construction of a new model of organizing education, taking into account digital opportunities.

The dominant value of pedagogy is always a person and all other areas of scientific action should be focused on him. One of the solutions seems to be the formation and dissemination of the cognitive paradigm of education, based on the appeal to multilevel methods, types and technologies of thinking, perception and processing of information in order to create the subject of his own system of knowledge and ideas in a specific subject area: the sphere of academic disciplines, the sphere of the teacher's activity and activities of the educational organization as a whole [1]. While creating the internal environment of the

${ }^{*}$ Corresponding author: frau.levina2010@yandex.ru 
educational system and supporting the cognitive processes of human development, the question of organizing multidimensional educational opportunities in the era of digitalization remains open. In this context, the scientific community is increasingly beginning to discuss the issue of educational ecosystems.

According to the ecological concepts, an ecosystem is a biological system consisting of a community of living organisms (biocenosis), their habitat (biotope), a system of connections that exchange matter and energy between them [2]. "Environmental friendliness" in this context appears as the preservation of the integrity of the surrounding world when performing any actions.

The educational ecosystem takes its origins from the ecological study of human behavior, designating ecology (educational ecology) as a way of studying the connections of educational structures, organizations and systems, for example, D. Ashby (1966), L. Gremin (1977), etc [3]. The interconnectedness and multidimensionality of educational processes determines the balance of the educational system.

Lacking a stable definition at the moment, many researchers represent the educational ecosystem as a network, it is "an innovative social and educational network that unites formal and non-formal educational institutions, all members of the community with their educational needs, has a variety of sources of financial, educational and other resources and aimed at ensuring innovative social and economic development" [4].

Researchers at the Higher School of Economics (Russia) believe that the vector of the future is the real involvement of education actors in the process, when "learning will be closely related to the real world and its problems, will involve the rich culture and knowledge of local communities"[5]. It is necessary to clarify that Russian education is mostly controlled by the state, its specially created ministries and departments; therefore, the idea is correlated with the idea of implementing the guidelines of state-public education management, involving all interested parties (individual, state, business, family, society) [6, 7].

In our opinion, there are several significant gaps in such interpretations. Let's designate only some of them.

First, a humanitarian vision of sustainability is not presented. The classical pedagogical principle of "not harming", together with an orientation towards teaching, upbringing and personal development, constitutes the basis of Russian pedagogy, having put down deep roots more than 2 centuries ago. Environmental friendliness in such a view should develop in relation to all subjects of education and the educational environment, focusing, however, exclusively not on existence, but on the development of the person of the future and the preservation of traditional cultural values and meanings.

Secondly, the network organizational structure of the educational ecosystem should not only have a single coordination mechanism, but should determine a multitude of controlled (self-controlled) trajectories for achieving educational performance with a clear goal-setting and a set of actions for education actors. At the same time, all educational content should be informatively significant, carefully reviewed and aimed at innovative human development. Thirdly, reliance solely on the educational opportunities and needs of students cannot always ensure their relevance in the labor market after training, as a result of which a person may become socially and economically unclaimed. Here it is clearly necessary to coordinate the interests of all actors in education in order to build a harmonious trajectory of a person's personal and professional development.

Information openness, the global spread of alternative sources of knowledge and new digital opportunities create a huge layer of educational trajectories. A description of their systemic complexity, the formation of new mechanisms and models of learning based on the non-subject integration of knowledge, the activation and involvement of students, the design of their own learning, taking into account the need for lifelong education throughout 
life in our dynamic world, based on the environmental friendliness of the goal, process and result of education.

The purpose of the article is to substantiate the characteristics of the educational ecosystem from the standpoint of achieving the quality of education.

\section{Methodology for the development of educational ecosystems}

Let us briefly present the methodology of our research.

1) Our vision is the prototype of a virtual universal educational organization (mixed format of online-offline processes), which recreates its own educational environment, tuned to the educational needs and capabilities of each person. We understand it as a special dynamic educational infrastructure, in which, by combining a multitude of subjects of educational processes and digital technological capabilities, conditions for learning and professional and personal development of a person are provided. This system should be hierarchical and manageable, and based on the environmental friendliness of all processes and pedagogical interactions of education actors.

2) When organizing educational processes, we base on the practical implementation of the principles, mechanisms and tools of cognitive pedagogy as a new socio-humanitarian knowledge. Cognitive pedagogy is based on the management of the processes of obtaining and generating knowledge, referring to the methods, types and technologies of information processing by a person, the processes of perception and processing of knowledge, their generation as the basis for the development of a Person, a community of people and the creation of innovative products and technologies [8]. The need for pedagogical interactions between generations of people with fundamentally different mechanisms of perception (analogue and digital generations) makes this area especially relevant [9], which globally complicates the transfer of the system of knowledge and sciences.

3) Environmental friendliness in this context means value-stable cognitive foundations of educational activities in a digital format, based on the rational interaction of educational subjects. In the educational ecosystem, a person is considered as "an integral phenomenon, both sociocultural and biosocial" [10]. Humanity, environmental compliance and social compliance are the core of a new educational paradigm to ensure the future prosperity of society in a modern turbulent environment.

4) Digitalization is a natural milestone in the technological development of mathematics, cybernetics, informatics, based on scientific and technical and technological achievements, interdisciplinary connections and continuity of methods, forms and technologies. If informatization has given us the opportunity for non-professional access to various information objects through global communications, then digitalization extends information processes to all spheres of life, "freeing" us from routine operations for other needs of the person himself and society, those where exceptional "human" qualities are needed. The continuity of scientific knowledge in this area is the metaprinciple of our research.

5) The multiplicity of hierarchies and positions of the educational ecosystem in each subject case is determined by the content and communications between participants in educational processes. Strategies for the harmonious implementation of this provision are [1]: 1) an information-cognitive approach that "works" with the processes of managing the generation of knowledge of subjects and objects of education and considering the variety of options for the development of events in the peculiarities of education: personal orientation, high variability of educational situations, cyclicality of all educational processes, temporary limitation, etc.; 2) a socio-cognitive approach aimed at a person's mastery of culture-like, nature-like and professional meanings in the framework of education, their transformation 
into their own concepts of life based on a person's personal ability and self-organization mechanisms when processing new information and generating knowledge.

The highlighted theoretical basis applies to all components of the educational ecosystem that require development.

\section{Research results}

1. Correlation between the concepts of "educational space", "educational environment", "educational ecosystem".

Space from the standpoint of metric systems can be defined by a set of vectors with a certain set of limited rules of action (axioms). From a philosophical standpoint, educational space is defined in two ways: 1) as the world of educational objects; 2) as an object of subjective activity that forms this space [11]. From the standpoint of pedagogy, we believe that the educational space can be interpreted as a set of objects of education and pedagogical interactions of subjects of education.

Within the framework of the educational space, educational systems operate, ordered by levels of education and including a clear hierarchy of educational standards, educational organizations, executive state bodies exercising control and supervision over educational activities, as well as other education actors (employers, members of the public, science, etc.). In a sense, each educational organization can act as a component of the educational system of a certain level of education (preschool, general, secondary, higher - for Russian gradation).

Taking into account the initial stage of development of the ecosystem approach in education, we believe that now only strategies for the creation and development of educational ecosystems and its pedagogical practices, both in the digital space and outside it, are being formed and worked out $[12,13]$. In the authors' view, the educational ecosystem is a subsystem of the educational system, includes elements of educational, natural and social ecosystems, is expressed through the material information system and the implementation of educational functions in a certain space-time range.

The period of the pandemic has shown new educational opportunities for hybrid (blended learning), which, according to experts, will be implemented in the post-like world, therefore, we believe that considering a digital educational ecosystem and a non-digital one is inappropriate. In our view, there are no boundaries between them; digital technologies and the level of their implementation determine the range of possibilities of the educational ecosystem.

Around educational ecosystems, their own educational environments are created external and internal environment. The external educational environment is a part of the socio-economic system that sets external conditions and requirements for the implementation of educational activities (formal, informal). The internal educational environment is the immediate state of a dynamic educational ecosystem (an ecosystem organism) at the current moment of time, dictated by established strategies, pedagogical rules, situations of pedagogical interactions of educational subjects and local organizational and pedagogical conditions.

2. The structure of the educational ecosystem.

Educational ecosystems are built on the network interaction of objects and subjects of education with a focus on human conformity, personal and professional development of a person and groups of people throughout life.

There is a need for typologization of the characteristics of educational ecosystems, identification of its elements, "ecological niches" of education, the specifics of relations with natural and social systems. The viability of the educational ecosystem is determined by the needs of the subjects of education, the effectiveness of training in the unity of 
structure and function, contributing to the sustainable and harmonious development of education in a comprehensive, systemic and natural way $[14,15,16]$.

The authors propose to consider the essence of the educational ecosystem through the prism:

- relations: "man-man" and "man-society"; human-like and human-centeredness are the core of a new educational paradigm to ensure the future prosperity of society in a modern turbulent environment;

- pedagogical interactions: "person-person" and "person-society", which are revealed in detail in the description of dichotomies of subjects of education, actors of education, objects of education and society;

- educational environment, formed through the triad "society-university - family" in interaction with the global educational space;

- orientation towards the quality of education, through a system of factors and requirements (pedagogical, psychological, environmental, aesthetic, economic, etc.);

- educational strategies and technologies focused on achieving learning outcomes.

Higher education can be represented as a symbiosis of various internal factors of the education system and the interchange between education and the external social environment in such forms as: substances, energies and information, etc.

The relationship between higher education and the social environment has the same internal mechanism as the relationship between biology and the environment, which consists of the main body, the individual, the environment and other elements that have mutual influence and mutual restraint $[4,17]$. It is unlikely that we will be mistaken if we say that the university (the main body) should act as the center and provider of the ecosystem of education, which determines the key, including "ecological" positions of education aimed at the well-being and success of society.

It should be noted that the value of each element is embodied through others - this is the mechanism of a typical social ecosystem. In such an ecological system, the teacher teaches the student (in fact, the exchange of material and energy information within the system) or through social practice (that is, the exchange of material and energy information between systems), establishing a balanced development of system elements and maintaining stability for the sustainable and continuous development of the system of higher education.

The leading characteristic of the educational ecosystem is its dynamic balance, which manifests itself in the educational and social environment. Symbiosis is formed as a result of interaction between all of the above elements of the educational ecosystem, and the development of the internal structure of education itself strives for harmony and balance. The benchmark of higher education will be the prospect of maintaining a natural balance between the internal and external environment of the education system. Therefore, in order to follow the path of environmental development, higher education must follow the basic natural principles and values and moral norms.

3. Principles for the formation of an educational ecosystem

We have found that it is necessary to structure and ensure the interests of education actors of educational agents (personality, state, society, business community, employees of the education system), taking into account their interaction, the inevitable conflict of interests and the level of influence on the activities of educational systems. Each of the actors has personal and social interests, while there is a so-called tendency of "growth of expectations", when the social responsibility of the educational system to society has increased several times $[18,19]$. The ecosystem approach is the answer to the demand for increased social responsibility of the education system.

Hence, the conclusion follows - when developing and implementing educational ecosystems, it is necessary to ensure a balance of interests and leveling the contradictions of all actors in education. We believe that the reliance on the idea of J. Juran [20], the 
presentation of quality as both a planned result and a strategic resource, fully determines the environmental friendliness of system requirements, allowing to integrate the interests of all actors in education and ensure the effectiveness of the educational ecosystem during its continuous development.

The principles of quality management (ISO 9000: 2015) are disclosed through the basic guidelines that fully correlate with the environmental friendliness of education:

- "customer orientation" as meeting consumer requirements and striving to "exceed expectations" as a range of educational services based on human conformity;

- "leadership" and "employee involvement" as ensuring the unity of goals and development of educational services through innovative knowledge and mechanisms for the implementation of educational activities, that is, the generation of knowledge by subjects of education in the field of science and education;

- "implementation of the process approach", through the detailing and management of interrelated and interacting processes of educational activity that function as an agreed ecosystem through the special principles of the ecological chain;

- "continuous improvement" as maintaining the dynamic development of educational ecosystems while maintaining the harmonious balance of the development of a modern person;

- "monitoring" of educational activities and "management of relationships" for the formation of a sustainable educational environment for the generation of knowledge and cultivation of talents.

The basis of the quality management standard ISO 9001: 2015 can be presented as the formation of educational ecology in relation to: issues of responsibility for the quality of education (educational processes provided by the ecosystem); increasing the socioeconomic efficiency of educational activities at the regional level; increasing the satisfaction of educational actors; to the management system for the development of an educational organization, taking into account the assessment of the risks of environmental friendliness of education.

\section{Conclusions}

a) We are currently in the process of forming an educational ecosystem that is unlimited, multidimensional and dynamic. The plurality of definitions and ideas about it, including those already actually realized, do not yet allow us to give a single vision of its generalized characteristics, functions and mechanisms.

b) A global formulated approach to the development of educational ecosystems has not yet been formalized. The author's analysis of research and practice in the development of educational ecosystems made it possible to identify the main problems of ecological methodology: i) the lack of humanitarian pedagogical approaches in the formation and development of ecosystems; ii) insufficient governance structures and manageability of educational ecosystems; iii) the complexity of the normalization and standardization of education, the lack of practical orientation to the quality of education in demand by society.

c) The authors have established meta-principles for the formation of educational ecosystems, based on the cognitive paradigm of education: human conformity, nature conformity, social orientation. These principles: recreate the necessary connections and coordinates of the pedagogical interaction of education actors; form the features of the organization of the educational environment for the development of the system of knowledge and sciences, the cultural and value dialogue of times.

d) The introduction of practical, well-proven quality management mechanisms in the educational ecosystem reflects the degree of its social responsibility for the effectiveness of 
educational activities, contributing to the expansion of the range of unique reserves and mechanisms for organizing and self-organizing educational processes at the university.

\section{References}

1. R. Kh. Gilmeeva, A. R. Kamaleeva, A. S. Katz, E. Y. Levina, and all. Cognitive pedagogy: teaching aid. (2020)

2. A. A. Zholdasbekov, Z. S. Sikhimbaeva, Z. A. Shyngysbaeva. Research of problems of ecological education of students. Modern problems of science and education. 1 (2012)

3. G. V. Vanykina, T. O Sundukova. The ecosystem model of higher education. Modern problems of the formation of a healthy lifestyle among students. (2020)

4. D. A.Savkin, E. A.Loktionova, D. I. Khlebovich. Greenfield in the ecosystem of higher education: the case of the BRICS Baikal Institute. Educational Studies Moscow. 4 (2020)

5. P. Luksha. Educational ecosystems for the development of society. Education 20.35. Man. ASI.(2017)

6. E. N. Prokofieva. Educational risks within the framework of cognitive management: theoretical aspects. Kazan Pedagogical Journal. 4 (2018)

7. E. Y. Levina. To the problem of managing the development of education: a stakeholder approach. Kazan Pedagogical Journal. 6 (2015).

8. E. Y. Levina, L. Yu. Mukhametzyanova. Human development of knowledge in the perspective of the cognitive paradigm. Kazan Pedagogical Journal. 3 (2020)

9. M. Barak. Are digital natives open to change? Examining flexible thinking and resistance to change. Computers \& Education. 121 (2018)

10. E. V. Petrova. Ecology of the cognitive and educational space of the digital age. Education Development. 3 (2019)

11. S. V. Ivanova. Educational space and the educational environment: in search of differences. Values and meanings. 6 (2015)

12. G. B. Kleiner. University as an Ecosystem: Institutes of Interdisciplinary Management. Journal of Institutional Studies. 11 (2019)

13. R. Adner. Ecosystem as Structure: An Actionable Construct for Strategy. Journal of Management. 43 (2017).

14. N. V. Gerasimov. Competitive environment as a factor in the formation of the university innovation ecosystem. Postulate. 6 (2018)

15. T. Fedorov. Moving from an educational environment to an educational ecosystem. Young Scientist. 28 (2019)

16. T. Xu. Research on Ecosystem Model and Elements of Innovation and Entrepreneurship Education in International Higher Education: A Case Study of MIT. Journal of Distance Education. (2017)

17. Y. Sitenko. The role of the university in the regional innovation system. The Journal of Economic Research \& Business Administration. 4 (2018)

18. D. O. Koroleva, T. E. Khavenson Innovators from within and from without the education system. Reforms and Innovation in Education - Implications for the Quality of Human Capital (2017)

19. O. Kolomytseva, A. Pavlovska. The Role of Universities in the National Innovation System. Baltic Journal of Economic Studies. 6 (2020)

20. J. M. Juran Strategic Quality Management. Juran's Quality Control Handbook. 6 (1992) 